\title{
A case of femoral arteriovenous fistula caused by central venous catheterization under inadequate ultrasound guidance
}

\author{
Daiki Nakashima* ${ }^{*}$, Shinobu Yamaguchi, Kumiko Tanabe, Woo Kim and Hiroki lida
}

\section{To the Editor Background}

Arteriovenous fistula is a rare but severe complication of central venous catheterization $[1,2]$. The use of ultrasound guidance for central venous catheterization is recommended to improve the success rate and reduce complications [3]. However, a safe procedure cannot be performed without adequate knowledge and skill.

\section{Case presentation}

A 77-year-old woman was diagnosed with meningioma on the left frontal cerebral falx and scheduled for tumorectomy in the supine position. Under general anesthesia, her right lower extremity was abducted and externally rotated in the supine position for central venous catheterization to the right femoral vein to prepare for intraoperative bleeding. Prescanning for catheterization with ultrasound (SonoSite M Turbo $^{\circ}$, FUJIFILM@) using linear probe was performed. Although the femoral artery and femoral vein did not overlap at the inguinal ligament level, both vessels overlapped toward the periphery. An ultrasound probe was placed $1 \mathrm{~cm}$ peripheral from the inguinal ligament, and the skin insertion point of the needle was $3 \mathrm{~cm}$ peripheral from the inguinal ligament (Fig. 1). The puncture was performed once using real-time ultrasound guidance (short axis view/ out-of-plane approach), and where the needle tip punctured, the target vein was visualized. A central venous double lumen catheter (SMAC Plus ${ }^{\circ}$, COVI-
DIEN $^{\mathrm{su}}$ ) was inserted smoothly using the Seldinger technique, and reversal of the venous blood was observed.

When the central venous catheter was removed 6 days after the operation, arterial bleeding was observed. The bleeding stopped by compression with hands. Color Doppler ultrasound and contrast computed tomography detected arteriovenous fistula between the right femoral artery and femoral vein 8 days after the operation (Fig. 2). Angioplasty was performed 15 days after the operation.

\section{Discussion}

In our case, catheterization into the right femoral vein after penetrating the right femoral artery caused femoral arteriovenous fistula. The issue with the manipulation in this case was considered to be the gap between the probe and the needle insertion point of the skin preventing visualization of the needle tip at all times. Therefore, the penetration of the femoral artery by the needle was not recognized. When a central venous catheter is inserted with real-time ultrasound guidance (short axis view/outof-plane approach), the skin insertion point should be located right next to the probe, and the needle tip should be visualized at all times until the target vein is punctured. In 2014, several key attributes for teaching safe ultrasound-guided central venous catheter insertion were proposed as follows: (1) a curriculum clearly describing the technical approach and cognitive elements required, preferably with video-based procedural examples; (2) hands-on

* Correspondence: isi_m2001046@yahoo.co.jp

Department of Anesthesiology and Pain Medicine, Gifu University Graduate School of Medicine, Gifu 501-1194, Japan 


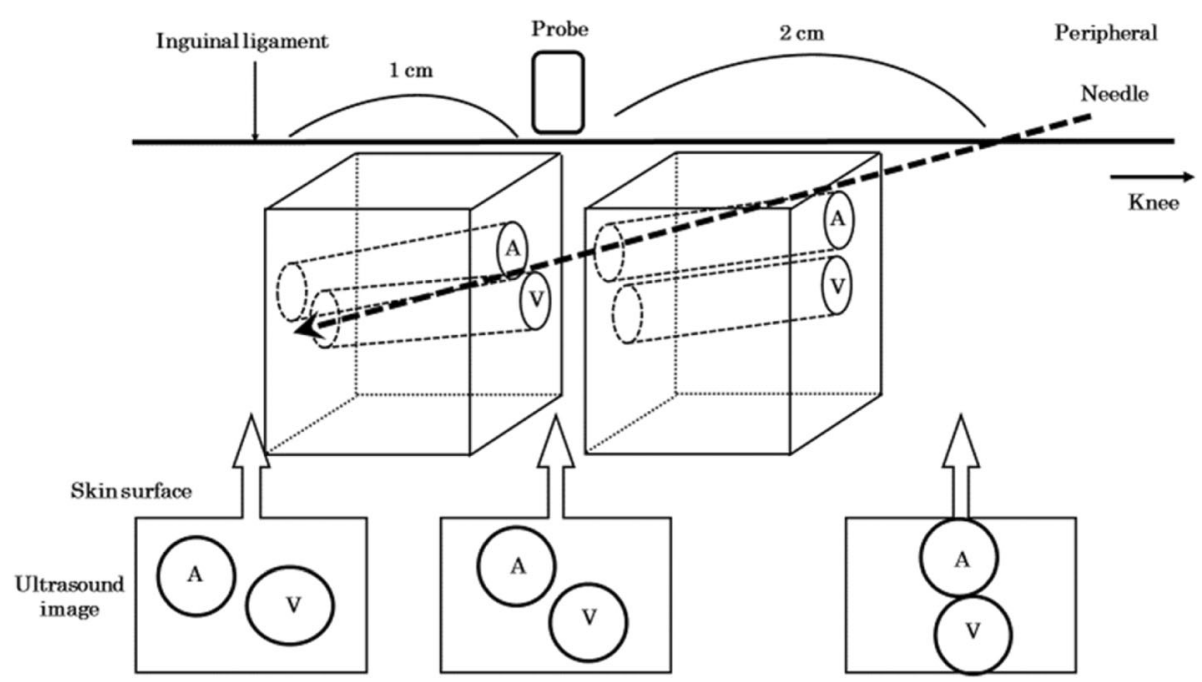

Fig. 1 Scheme illustration of the relationship between the needle and ultrasound image. The femoral artery and femoral vein did not overlap at the inguinal ligament level. However, both vessels overlapped toward the periphery. The figures below are ultrasound images at each point. A femoral artery, $\vee$ femoral vein

simulation training to develop hand-eye skills; (3) an emphasis on techniques that allow visualization of the needle tip at all times; and (4) insertions supervised by experienced clinicians giving feedback for improvement [4].

\section{Conclusion}

Central venous catheter insertion is an invasive procedure that can lead to severe complications. When a central

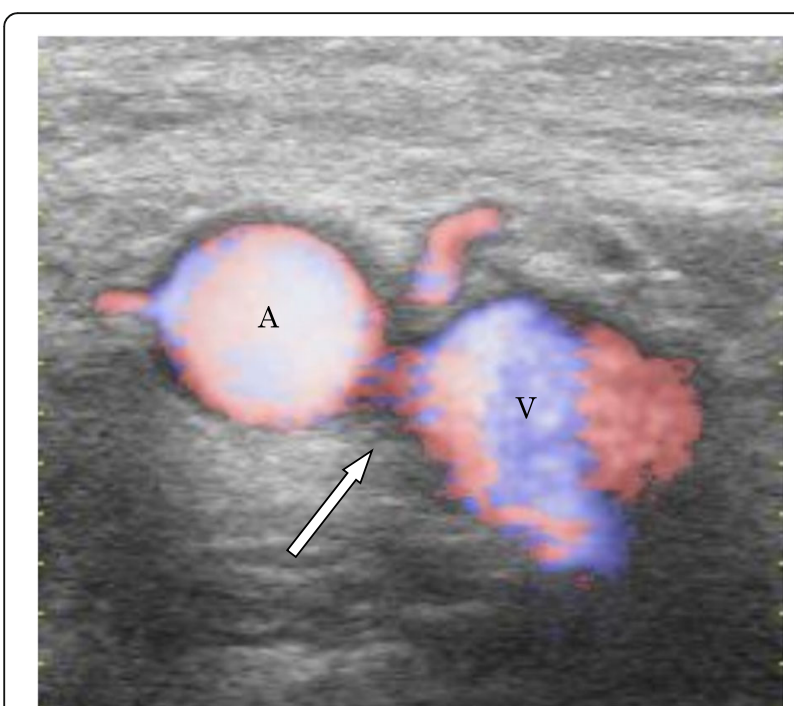

Fig. 2 Color Doppler ultrasound findings of an arteriovenous fistula between the right femoral artery and the right femoral vein. A femoral artery, $\vee$ femoral vein, arrow fistula venous catheter is inserted with or without real-time ultrasound guidance, we must ensure it is adequately inserted.

\section{Acknowledgements}

Not applicable.

\section{Funding}

None.

\section{Availability of data and materials}

Data sharing is not applicable as no datasets were generated or analyzed during the current case report.

\section{Authors' contributions}

SY, KT, WK and HI read and approved the final manuscript.

\section{Ethics approval and consent to participate}

The patient provided her informed consent for the publication of this case report.

\section{Consent for publication}

We obtained consent in writing for publication from the patient.

\section{Competing interests}

The authors declare that they have no competing interests.

\section{Publisher's Note}

Springer Nature remains neutral with regard to jurisdictional claims in published maps and institutional affiliations.

Received: 1 February 2018 Accepted: 13 March 2018

Published online: 04 April 2018

\section{References}

1. Jin L, Wang J, Wu C, Shao C, Yu X, Lei W. Femoral arteriovenous fistula associated with leg swelling 6 months after removal of a hemodialysis catheter: a case report. Medicine. 2015; https://doi.org/10.1097/MD. 0000000000001738 .

2. McGee DC, Gould MK. Preventing complications of central venous catheterization. N Engl J Med. 2003;348:1123-33. 
3. Dietrich CF, Horn R, Morf S, Chiorean L, Dong Y, Cui XW, et al. Ultrasound-guided central vascular interventions, comments on the European Federation of Societies for Ultrasound in Medicine and Biology guidelines on interventional ultrasound. J Thorac Dis. 2016;8: 851-68.

4. Schmidt GA, Kory P. Ultrasound guided central venous catheter insertion: teaching and learning. Intensive Care Med. 2014;40:111-3.

\section{Submit your manuscript to a SpringerOpen ${ }^{\circ}$} journal and benefit from:

- Convenient online submission

- Rigorous peer review

- Open access: articles freely available online

- High visibility within the field

- Retaining the copyright to your article

Submit your next manuscript at $\boldsymbol{\sim}$ springeropen.com 